\title{
Towards a Confucian Geopolitics
}

Ning An, Jo Sharp and Ian Shaw

\begin{abstract}
In this paper, we argue that Confucian philosophies are vital to understanding contemporary Chinese geopolitics. Existing Western geopolitical frameworks, we contend, are insufficient for grasping the complex theories and historical legacies that underpin China's foreign policy. This issue becomes particularly salient as scholars and the public alike try to manage complex and changing geopolitical ideas underpinning the Belt and Road Initiative, recently heralded by the Chinese state and epitomising China's ambition for expanded global engagements. This paper provides a much-needed critical assessment and review of Confucian ideas and their uptake in Chinese state theory, geographic imagination, and geopolitical scripts. While Confucianism typically focuses on ideals of harmony, hierarchy, and normative social order, geopolitics analyses geographical influences on politics - in particular, violence and conflict. However, it is precisely within this contradictory dialectic that new possibilities for analysing the geopolitics of a rising global power can emerge.
\end{abstract}

Keywords: Geopolitics, Confucianism, China, State, Foreign policy, Political geography

\section{Introduction}

China $^{1}$ is an increasingly important player in the international political and economic arena, and its geopolitical influence continues to grow through its role in BRICS (an association of five major emerging national economies: Brazil, Russia, India, China, and South Africa), the Belt and Road Initiative (BRI), and the Forum on China-Africa Cooperation (FOCAC) (see 
Carmody and Owusu, 2007; Maswana, 2009; Park, 2015; Sidaway and Woon, 2017; Blanchard and Flint, 2017; Brewster, 2017). Like many other states, Chinese geopolitics are deeply embedded in global geopolitical trends, yet still rest on a unique set of cultural, economic, and political assumptions that differ markedly from other states. Several scholars who focus on Chinese studies (see Kang, 2007; Jacques, 2009; Callahan, 2012) have tended to see China's values as diverging from rather than converging with these globalising values, even if they hold that China is becoming more integrated into the modern international system alongside its industrialisation, marketisation, and globalisation. For these writers, China is modernising in its own way by reworking its inheritance of traditional legacies. However, while Confucianism and its modern status have been widely discussed in some other fields like history or philosophy (Yao, 2000; Hang, 2011), it has rarely been discussed in conjunction with the concept of geopolitics. However, the leaders of the current Chinese state often use Confucian ideas to express their geopolitical deployments. Accordingly, it is vital to explore the complex links between Chinese geopolitics and the distinctly cultural legacy of Confucianism.

Previous studies have analysed Chinese geopolitics through the lens of Communist geopolitics, placing Chinese geopolitics (both narratives and practices) in the binarism of communismcapitalism (e.g., Treadgold, 1977; Li, 1993; Shlapentokh, 1995). Other studies have used nationalism as a lens to observe Chinese geopolitics (e.g., Hughes, 2000; Zhou, 2005; Wu, 2008; Manson, 2010; Xu, 2012; An et al., 2016). The nationalist approach explains Chinese geopolitics through a dichotomous framework of 'Chineseness' and 'non-Chineseness' in which patriotism and national identity (rather than the cultural identity of Confucianism) are regarded as the foundation for Chinese geopolitical visions. Finally, realist geopolitics—which focuses on politicians' ambitions for national security as a fundamental factor, triggering international politics (Dalby, 2013) — has also been put forward as an explanation for Chinese 
geopolitics. Realist thinking is predominantly informed by geo-security (e.g., Overholt, 2007; Scott, 2008; Liu, 2009) and geo-economy (e.g., Zhang, 2009; Zeng et al., 2015; Rolf and Agnew, 2016). These approaches reveal a common belief that the security of China's territorial and economic interests is the core driver of Chinese geopolitics.

This work on Chinese geopolitical theories, however, tends to overlook the influence of distinctly Chinese cultural and normative values (An et al., 2017) despite a few noteworthy exceptions (see Callahan, 2010; Agnew, 2010, 2012; Park, 2015; Woon, 2012, 2018). For instance, Callahan (2010) deduces China's international relations discourse logic by analysing contemporary Chinese narratives of national shame, and by doing so, argues that the 'civilisation and barbarism' distinction (also called the 'Hua and Yi' distinction, which will be discussed later) emphasised in traditional Chinese political culture continues to frame the Chinese understanding of geopolitical identity and national security. Park (2015) tries to use the traditional Chinese notion of 'Sino-centrism' as a superordinate concept that encompasses China's historical and current developing path to explain China's increasing capital investment in Africa, whereas Woon (2018) unpacks China's historical narratives of Sino-centrism, and in doing so examines how these historical claims to China's rise constitute deterministic accounts to provide discursive backing for China's self-defined geopolitical position in the coming decades. Although such disavowals are frequent in recent theoretical and empirical writings, what is notably absent from them is a consistent analysis of the cultural basis for Chinese geopolitical theories, thereby advancing an alternate geographic understanding of the geopolitical aspect of China's ascent. To achieve this aim, we draw on the development of Confucian philosophies in different historical moments to convey traditional Chinese political culture. Thereafter, we will analyse national foreign policy texts of the Chinese government to explore contemporary influences of Confucianism on Chinese geopolitics. In doing so, we will 
present a model of Confucian geopolitics that embeds Confucian philosophies within the explanations of Chinese geopolitics. In this regard, this paper aims to provide a far more nuanced analysis and genealogy of Chinese geopolitics.

To present our model of Confucian geopolitics, this paper is divided into three sections. The next section (II) outlines classic Confucian theory, defining its geopolitical dimensions in terms of its spatial division of the world. Subsequently, in Section III, we explore the extent to which classic Confucian theory helps describe the geopolitical narratives of the modern Chinese state. Through this exploration, we argue that current Chinese geopolitics is evidently more than simple classic Confucian theory. Thus, in Section IV, we propose a hybrid Confucian geopolitical theory as a more effective lens for examining the entanglement of Chinese cultural values with the geopolitical narratives of today. Throughout this paper, we distinguish between narratives and practices. We do so to emphasise how the strategic appropriation of Confucian narratives can be used to legitimise state actions that both converge with and diverge from Confucian accounts of morality and philosophy. In other words, narratives can directly express and shape strategic actions (as 'ideal types'), but they can also be used to mask and hide practices that directly contradict narratives (as with the case of neoliberal reform since the 1990s). In either case, Confucian narratives are used to support Chinese state practices on the domestic and global stage.

Given that Confucian geopolitics advocates a set of historically-rooted but often implicitly stated cultural and normative values, it is theoretically and empirically valuable to tease out the complex and changing Chinese geopolitical ideas underpinning Chinese geopolitical projects in current times (the BRI in particular), which previously received scrutiny mainly within Western geopolitical optics (Sidaway and Woon, 2017; Blanchard and Flint, 2017; Brewster, 
2017). Thus, this paper also serves as an empirical contribution because it would serve as a springboard towards an alternative understanding of these geopolitical projects, even though detailed empirical unpacking of these projects is only a secondary purpose of this paper. Taking the BRI as an example, the notions of mutual learning, complementarity (huxue, hujian, hubu), and a community of humankind's shared destiny (renlei mingyun gongtongti) all reflect Confucian geopolitics' pursuit of the ideal geopolitical order-'harmony in difference' (i.e. seeking similarity without eradicating differences). This paper does not dwell at length on this issue but certainly broaches an opening for nuanced empirical work in the future.

\section{Harmony, Hierarchy, and Order: Classic Confucian Theory}

\section{Confucianism}

The Zhou Dynasty (1056 BCE-256 BCE) was the earliest era when ancient Chinese ritualistic culture was formulated. This ritual culture was called Zhou $\mathrm{Li}$, which was an important foundation for the maintenance of social order in the Zhou Dynasty. Nevertheless, as the emperor's power gradually declined at the end of the Zhou Dynasty, ancient China split into several small states, during which these small states pursued military force rather than Zhou Li as the basis for gaining power and maintaining order. At that time, a loyal supporter of Zhou Li named Confucius (551 BCE-479 BCE) put forward the ethical and political mindset of Confucianism, which was completely different from realist politics, and he attempted to impart this concept to the emperors of that era.

Confucianism attaches great importance to the basic values of humaneness and harmony ('humaneness for others, harmony and order' [ren yi churen, hexie youxu]) is considered the core value in Confucianism (see Wang, 2018). Moreover, Confucianism advocates individual 
cultivation (becoming a sage of moral character) as a source of political legitimacy, and believes in the power of morality as the basis for shaping order (see Li, 2013). However, in a time of chaos, Confucianism seemed both soft and powerless, and consequently, Confucius's ideas were not very influential. In this context, he became a teacher and spread his Confucian mindset to a wider population. Confucianism in this period was called 'pre-Qin Confucianism', and since then, it has undergone two major changes in ancient Chinese history: one during the Han Dynasty, and the other during the Tang, Song, and Ming Dynasties.

The first major change occurred during the Han Dynasty (202 BCE-8 CE). In fact, until the early Han Dynasty, Confucianism and its ethical political ideas were still not integrated into the political fabric by rulers. Consequently, supporters of Confucianism began to reconsider and reform the Confucian mindset. One of the most representative transformers of this period is $\mathrm{Lu} \mathrm{Gu}$, who had an intense debate with the first emperor of the Han Dynasty, arguing that gaining power in a state is extremely different from governing a state (Ren, 2001). Such a debate made the rulers of the Han Dynasty realise the significance of Confucianism in safeguarding the emperor's power, and Confucianism has thus become the only ruling thought of the Han Dynasty, called the 'Confucianism-only ideology' (bachu baijia, duzun rushu) (Chen, 2005). In this way, Confucianism entered onto the stage, guiding Chinese political practices, while it was also evolving into a kind of imperial art being widely used for maintaining imperial power. Compared with pre-Qin Confucianism, Confucianism in the Han Dynasty had been reformed in several aspects. From the perspective of ideological sources, Confucianism in the Han Dynasty not only inherited pre-Qin Confucian values but also combined values from other ideologies (like Taoism, legalism, and Yin-Yang theory) to improve its theoretical weaknesses and better adapt to the governance needs of the ruling class (Han, 1999). 
From this perspective, Confucianism in the Han Dynasty has been characterised by greater diversity, which inevitably led to a different understanding of the early concepts of Confucianism. For example, in pre-Qin Confucianism, the concept of harmony is an ideal political order, representing a stable and orderly social mode (Chen, 2015). However, in Han Confucianism, the concept of harmony was more clearly used to refer to 'the Great Unification' (da yi tong), an inclusive concept that was more in line with the will of the ruling class (Han, 1999). Importantly, Han Confucianism had experienced a process of sanctification (Sun and Ge, 2017). That is, in pre-Qin Confucianism, Confucius emphasised implementing humane governance (ren zheng) as the basis for emperors' political legitimacy, which could be interpreted as a simple humanism of spirit. However, Han Confucianism put forward the concept of 'monarchical authority' (junquan shen shou), which endows political legitimacy with more mysterious and supernatural factors (Han, 1999). The changes in Han Confucianism provided a more convenient theoretical basis for the ruling mindset.

The second major change happened in the Tang (618 CE-907 CE), Song (960 CE-1279 CE), and Ming (1368 CE-1644 CE) Dynasties. Confucianism found great success in the Han Dynasty, but its social status and significance have gradually declined since the Tang Dynasty. An important reason for this decline was the penetration of external cultural forces (mainly Buddhism in this period). Specifically, in that era, Confucianism was viewed as a series of moral principles; conversely, Buddhism had a more mature and complete theoretical system, including a cosmology at the ontological level. This challenge to Confucian theory by external cultures forced Confucian scholars to reinvent Confucian theory (Ning, 1998). Consequently, Confucian scholars gradually established a new Confucian theoretical system, namely neoConfucianism (also named Song-Ming Lixue). The progressiveness of neo-Confucianism is 
manifested in the more extensive and in-depth explanatory power of its theoretical dimension. The main representatives of neo-Confucianism are Zhu Xi and his disciples. In this school, Confucian scholars established a set of ontologies for Confucianism, which they named Li-Qi Theory (liqi lun). It posits that $L i$ (the natural law as well as the basic principles of ethics) is the origin of all things in the universe, while $Q i$ refers to the material that composes everything in the universe (Pan, 2011). In their opinions, $L i$ is the first nature of the world, which is the meridian of the world, while $Q i$ is the second nature and the structure of the world; together, they form the basic worldview for neo-Confucianism theory (Pan, 2011). What is most important for neo-Confucianism is that it creates a Realm Theory (jingjie lun) that pays more attention to people's self-cultivation through Confucian moral rules. Based on Li-Qi Theory, Realm Theory puts forward a view similar to asceticism, which places $L i$ (the Confucian principles) in opposition to human desire, insisting that human desire is the root of all evil. Thus, it requires people to use moral principles to restrain their desires (Ning, 1998).

Despite its constant transformation, Confucianism never deviated extensively from its basic ideals. The first is a moral activism, the basis for all behaviours of the social person and all actions of government. The most representative theory for this moral activism in Confucianism is the 'Confucian theory on morality-profit' (rujia yi li guan), which focuses on how to tackle the contradictions arising in the relationship between morality and profit. Pre-Qin Confucianism opposed the link between morality and profit, insisting that people should seek morality rather than profit. This doctrine was corroborated by Confucius in The Analects of Confucius: 'The man of honour seeks righteousness while the man of disgrace only cares about profit' (junzi yu yi, xiaoren yu li) (Legge, 2010: 71). However, over time this doctrine has been criticised by later Confucian scholars who tended to unify morality and profit. The most influential person in this school was Yan Yuan (a Confucian thinker in the early Qing Dynasty) 
who suggested acquiring profit based on morality, namely, 'The profit that the man of honour values is only the profit from righteousness' (yi zhong zhi li, junzi suo gui ye) (Yang, 2001: 23).

The second unchanging aspect for Confucianism theory is a state of 'sagacity within and kingliness without' (neisheng waiwang). Confucianism emphasises individuals' moral cultivation, which stretches beyond a purely moral and spiritual space for achieving personal self-transcendence and moves towards the wider realm of politics (Ge, 2000). In this regard, Confucian scholars insist that the premise of engaging in political activities is to promote personal moral cultivation. Only those individuals with a perceived good moral character (becoming a 'sage') were considered eligible to participate in public governance (Chen, 2015; Legge, 2010). On this basis, a politician or state's standing was viewed as legitimate; without it, the legitimacy of their rule might be doubted. This illustrates what the Confucian classic The Analects of Confucius (lun yu) calls the 'kingly way' (wang dao):

I have heard that rulers of states and chiefs of families are not troubled lest their people should be few, but are troubled lest they should not keep their separate places; that they are not troubled with fears of poverty, but are troubled with fears of a want of contented repose among the people in their separate places. For when the people keep their separate places, there will be no poverty; when harmony prevails, there will be no scarcity of people; and when there is such a contented repose, there will be no rebellious upsetting. So it is. Therefore, if remoter people are not submissive, all the influences of civil culture and virtue are to be cultivated to attract them to be so; and when they have been so attracted, they must be made contented and tranquil. (Chen, 2015: 67) 


\section{The Spatiality of Confucianism}

Confucianism also involves interesting discussions of geography. The geographical aspect of Confucianism is mainly reflected in its understanding of two geography-based concepts: 'Hua' and 'Yi'. 'Hua' and 'Yi' have each distinguished between different ethnic, economic, political, and cultural spaces over the course of Chinese history. For example, the spaces viewed as 'Hua' include areas inhabited by the Han Chinese, those having an agricultural or 'civilised' economy, those spaces under the direct political impact of the central government, and most importantly, spaces influenced by Confucian values. On the other hand, spaces viewed as 'Yi' include those inhabited by ethnic minorities, those with a nomadic economy, those that are out of the reach of the central government, and those that push back against Confucian doctrines. The Hua-Yi distinction reminds us of a similar theory originating in the Western world, namely Orientalism (Said, 1978), which rests on a series of geographic imaginations — again, juxtaposing an 'exotic' and 'wild' outside against a civilised interior. The difference between the Hua-Yi division and Orientalism is that while Orientalism fits into a convenient explanatory structure for the Western-centric geopolitical imagination, the Hua-Yi division establishes a Sino-centric, Hancentred (hereafter China-centred) geopolitical division.

Although the ethnic, economic, and political dimensions sometimes play an important role in understanding 'Hua' and 'Yi' in various historical stages in China, the most influential and dominant dimension for judging what is Hua and what is Yi is according to Confucian values. As Callahan (2004) suggested, this Hua-Yi distinction is more frequently understood as a discourse that takes shape as the opposition between civilisation and barbarism, rather than as a set of essentialist qualities such as race or ethnicity. What is important to note is that Confucianism has long been treated as the mainstream ideology by the ruling power (e.g. during the Zhou Dynasty, Han Dynasty, Song Dynasty, and Ming Dynasty) and thus has had a 
profound impact on Chinese political culture. Therefore, Chinese politicians usually referred to a Confucian framework to distinguish Hua from Yi (Wang, 2003). In this perspective, anyone following Confucianism is Hua; conversely, anyone not accepting Confucianism is Yi (Wang, 2003). Here, it merits emphasising in advance that the status of Confucianism itself has undergone intense transformation, even if its influence on Hua and Yi has remained considerable in modern China (Callahan, 2010). The cultural movement (e.g. the May Fourth New Cultural Movement in the Republic of China, and the Cultural Revolution in the People's Republic of China) has provoked a wide range of anti-Confucianism sentiment.

As a brief summary, the Hua-Yi distinction was applied across the divisions of different ethnic groups, economic systems, and political communities. However, to a great extent, the cultural identity (whether it fits into Confucian values or not) is viewed by Chinese politicians as the ultimate standard for dividing Hua and Yi. This is the most important part of Confucianism's spatiality. For example, Chu, a former Yi area located on the southern edge of China inhabited mainly by ethnic minorities, is viewed as Hua by other Hua polities because of its benevolence towards ordinary people in the spring and autumn of the warring states period (771 BCE-221 $\mathrm{BCE})$. 
Notes that explain the vague geographical locations, life features and histories of the tribes on the north.

\section{Map of Chinese and Barbarians}

The title of this ancient map

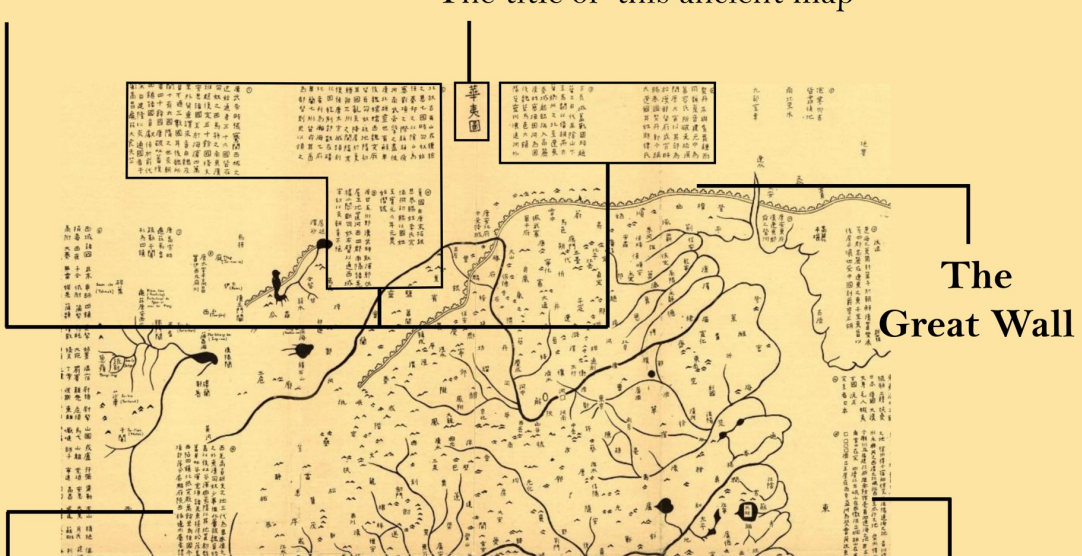

Note that explains the vague

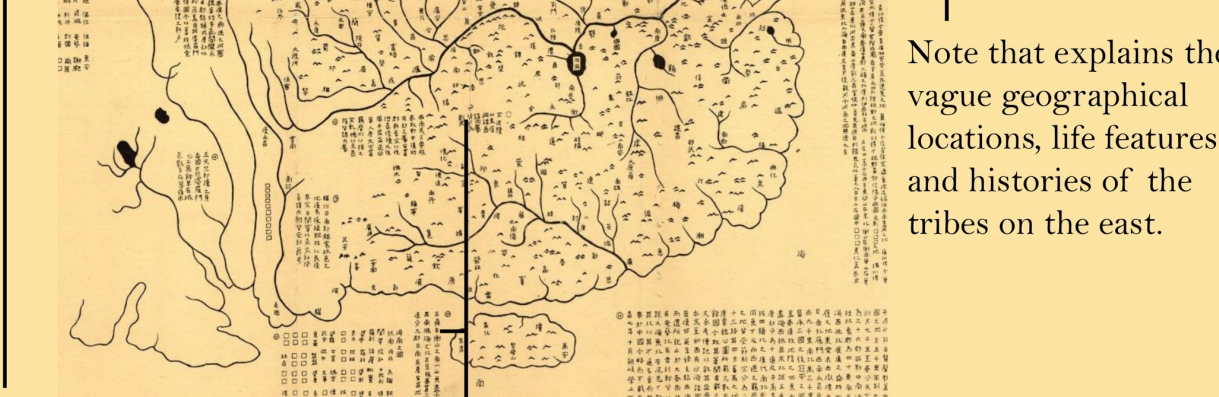
geographical locations, life features and histories of the tribes on the west.

Notes that explain the vague geographical locations, life features and histories of the tribes on the south.

Fig. 1. Map of the Chinese and the barbarians. This map identifies the Chinese (Hua) and the barbarians (Yi) in 1136, during the Song Dynasty. Source: Shaanxi Historical Museum, unknown author. The notes on the map have been added by this paper's authors.

From this brief history we can see that the Hua-Yi division has mapped a loose core (Hua)periphery (Yi) system, from which the most basic political geographical structure of ancient China is illustrated. This loosely political geographical structure between Hua and Yi can be evidently seen in an ancient map we found at the Shaanxi Historical Museum, which mapped the official Chinese understanding of the Hua-Yi division in the Song Dynasty (see Figure 1). In this map, we can see an open and borderless Hua (except the Great Wall from the north that divides Hua and Yi from the north, namely Di) with a basic terrain of natural mountains and rivers. In the four directions of the map, including the north with the Great Wall as a boundary, 
as well as the other three directions, the plotter used descriptive accounts to record the vague geographical locations, life features, and histories of the tribes on the edge (see notes in Figure 1). Even though this map pinpoints the approximate geographical distinction between Hua and Yi, we can clearly see that it does not delineate clear Hua-Yi boundaries, which can be interpreted as evidence for the fluidity and porosity between Hua and Yi identities. Despite its indeterminacy, this structure has provided the basis for national governance of ancient China, and it was because of this that the Hua-Yi division in this period was primarily limited to describing China's internal political, economic, and social relationships. However, the situation changed alongside the rise of the modern concept of 'nation-states' in the international arena that has largely impacted the understanding of Hua and Yi in Chinese society and thus influenced the formation of China's approach to foreign affairs. It is here that a globalising China began to rework the Hua and Yi geographic imagination. This story began from the Qing Dynasty (1644-1911) and the Republic of China, during which the word 'Yi' gradually evolved from a notion depicting Chinese ethnic minorities, nomadic economies, and undeveloped spaces into a concept describing nation-states outside China. This change can be traced back to a political crisis in the early Qing Dynasty. Qing China was founded and dominated by Manchu, a former Yi group (ethnically, economically, and politically) living in northeast China. According to Confucian values, it was legal for Yi groups to hold dominant positions only if they accepted Hua culture (Qi, 2000). That is, Yi groups had to erase their so-called 'barbaric' features if they were to occupy state positions. Hua culture thus became a kind of 'civilisational' standard.

However, the Manchu group did not abide by this Confucian value. Records show that the Manchu army slaughtered hundreds of thousands of people in some of the cities they seized (see the Chinese History Research Institute, 1982, for the archives on the Jiading and Yangzhou 
massacres during the early Qing Dynasty). Upon seizing control of the government, they continued to kill and exile Han Chinese; many were arrested for merely using the word 'Yi' to refer to the Manchu in their poems (from Shunzhi, the first emperor in Qing Dynasty, to Qianlong, the fourth emperor, there were approximately 130 poem prison cases in total; see Zhang and Zhang, 2010). The Han Chinese organised uprisings to resist the Manchu government. Simultaneously, international communications between Qing China and the outside world increased, giving Manchu governors an opportunity to label outsiders as 'Yi' (Liu, 2011). Consequently, Manchu governors deliberately established a 'Yi' discourse to refer to nations outside of China, to distance themselves from the derogatory 'Yi' label, and to alleviate Manchu-Han tensions. In this sense, for political reasons (the crisis between Manchu and Han) as well as geographical reasons (the Chinese people had a greater chance to obtain knowledge about the outside world), 'Yi' has gradually become a term referring to foreigners. Here, it is worth noting that in the late Qing Dynasty, because China had experienced failure in foreign wars (especially the Opium Wars), the derogatory term 'Yi' was resisted by foreign forces, and later a more positive term, 'Yang' (even better than 'Hua'), was adopted on a large population of Chinese society. In this context, the Hua-Yi binarism has been gradually obscured in Chinese society, particularly modern Chinese society.

Furthermore, the concept of 'Hua' has shifted from describing the Han Chinese and areas having a more advanced economy within the reach of the centralised government, to being characterised as a modern nation-state. Despite the fact that a large number of Chinese emperors had attempted to unify Hua and Yi into a 'Great Unity' (Liu, 2011), none were able to establish a state with nation-state significance until late in the Qing Dynasty when China as an agricultural country was challenged by international industrialisation. At that time, several Chinese politicians and scholars began to reconsider the meaning of 'Hua' (Feng, 2011). They 
used the Western concept of 'nation-state' to revive Hua. For instance, Liang Qichao (2006 [1902]), one of the most famous scholars during this period, created the concept of the Chinese nation, which included all Chinese ethnicities (see also Han, 2014). The proposal of the Chinese nation took hold, and today, Hua, broadly speaking, refers to China as a unified entity. What is also noteworthy is that this change is not a sudden one but rather a long historical process lasting hundreds of years. Most importantly, this new understanding of Hua and Yi has formed the basis of a modern Chinese approach to foreign relations.

\section{The Geopolitical Dimensions of Confucianism}

After mapping Confucianism and its spatial expressions, this section now explores the geopolitical dimensions of Confucianism in greater depth. The relationship between politics and space underpinned by Confucianism reflects and refracts Western concepts of geopolitics. The spatial divisions in Confucianism form an important basis for assessing the political relations among different socially compartmentalised polities or peoples like Hua or/and Yi (Xu, 2015). This structure can notably be read as a type of geopolitical thinking. Specifically, this Confucian geopolitical idea is featured in two aspects.

One of the most remarkable features of this Confucian geopolitics is its formation and emphasis on a Sino-centric hierarchy for the world being in order. For these Confucian politicians, the world is depicted as a geosystem (namely, the Tianxia system, meaning the universe system) fostered on the basis of the Hua-Yi division, by which Hua is viewed as the cultural centre with a high standard of morality, while Yi is treated as 'barbaric' (Zhao, 2008). In this system, a Hua-centred geographical, economic, and political order is maintained particularly by (but not limited to) the tribute system that requires the Yi to present tributes to the Hua (Zhao, 2008). As the word 'Hua' has long been equated with the ethnically Han Chinese (i.e. Sino), this 
system has been described as reflecting 'Sino-centrism'. The Sino-centric system was initially built on the difference between Hua and Yi, and gradually evolved into a more generalised geographical idea about the wider world. At first, the Hua were viewed as having cultural, material, social, psychological, and political superiority over the Yi due to perceived cultural differences (Qin, 2010). This superiority was translated geopolitically, with the Hua as the centre of the world, having the most fertile and populous lands and the most advanced and civilised values (Chen, 2015). In most Chinese dynasties, the Sino-centric hierarchy significantly impacted the government's ways of ordering space: the closer to Hua, the closer to power (Chen, 2015).

Even though the Sino-centrism has largely stayed at the level of describing China's internal political system for a long time in Chinese history (before the Qing Dynasty), it still has a profound impact on modern China's geopolitical images of the world. For example, when the British Mission first entered China in the 1790s and officially met with the government, British Ambassador Macartney was required to exercise courtesy as a representative of a peripheral state (i.e. the Yi) to the Qing Emperor Qianlong (Gao, 1999). The central status of the Hua (now referring to the Chinese nation) thus had to be remade so that the relationship between China (as a modern nation-state) and the outside world would resemble the tribute system that had existed between the Hua and Yi in pre-Qing Dynasty China. This new version of Sinocentrism placed China as the greatest world power, a 'celestial empire and superior state' (tianguo shangchao) with the most advanced culture in the world. In the meantime, foreign countries were imagined as barbaric, backward, and marginalised, having relationships that were subordinate to China (Chen, 2015: 70). This Sino-centrism, however, has faced fierce challenges from the frequent East-West encounters in the military, political, economic, and cultural realms since the later Qing Dynasty (especially after the two Opium Wars in the 1840s 
and the 1860s). Owing to the inferior position of China during these early East-West encounters, the new Sino-centrism swiftly collapsed during this era, deeply impacting the political and popular understandings of 'Chineseness' ${ }^{2}$ and 'the West' in current Chinese thinking. This is also the origin of the widely spread propaganda to realise the great rejuvenation of the Chinese nation in current Chinese society.

On the surface, the hierarchy between Hua and Yi appears like the (uneven) relationship between the core and the periphery as emphasised in conventional geopolitics. Nevertheless, the geopolitical visions in Confucianism are not the same as conventional geopolitical scripts. Such a difference is first reflected in the flexible (and historically shifting) boundary between Hua and Yi in Confucianism. As already noted, the notions of 'Hua' and 'Yi' are not completely synonymous with ethnicity, even though they frequently do carry those implications. Instead, the polities or peoples marked as 'Hua' or 'Yi' are usually capable of moving between the boundaries. The main criterion for judging whether a polity (or a group of people) is Hua or Yi is whether it accepts (or rejects) mainstream Confucian doctrines: if so, it would be categorised as Hua; if not, it would be dismissed as Yi.

The second, and perhaps most important, aspect of the Confucian geopolitical vision that diverges from conventional geopolitics is the emphasis on establishing a harmonious and orderly world system rather than a zero-sum game of power. Even though Yi is required to pay tribute to Hua in the Sino-centric geopolitical structure, the tribute can be a symbol of social etiquette and performance rather than a direct relationship of economic exploitation (Zhao, 2008). For example, on many occasions in Chinese history when Yi gives tributes to the central government, they usually receive more rewards from the emperor than the tribute itself was worth. Furthermore, unlike the realism that highlights a world of inevitable factions and a status 
of never-ending power struggles for geopolitical interests in conventional geopolitics (Dalby, 2013), Confucianism emphasises its political ideal of realising harmony. It is for this reason that Confucian politicians have resisted outright conflict when dealing with Hua-Yi relations, though of course they do not oppose warfare. Confucian politicians have sought to assimilate the Yi by spreading the advanced Hua culture to them; this way has been described as 'balancing Yi by Hua' (yi hua rang yi), 'changing Yi by Hua' (yi hua bian yi), and 'governing Yi by Hua' (yi hua zhi yi) (Qin, 2010: 15-16). In this condition, Confucian politicians had assumed that the Yi would recognise the more advanced nature of Hua culture, and would therefore want to learn from the Hua rather than start wars with them (Qin, 2010). Moreover, the idea of 'naturalisation', which is similar to some of China's current immigration policies, can draw from Confucian geopolitical strategies in tackling Hua-Yi relations. In this formulation, the (usually Hua-based) governmental policy would give (however selectively) preferential treatment to Yi populations (sometimes even better than they treat Hua populations) to assimilate them as Hua. For example, the historical study on ancient Chinese migration finds that, in many dynasties, the policy of mollification (huairou zhengce) adopted by (usually Han) rulers, especially with their emphasis on good living, a productive environment, and cultural awareness in Hua spaces, is one of the most important factors in motivating the migration of Yi populations (Li, 2004).

Of course, an official narrative of harmony and moral uprightness in Confucianism is sometimes at odds with China's geopolitical practices. In almost every dynasty in Chinese history there have been wars or other kinds of conflicts between the so-called 'Hua' and 'Yi'. This demonstrates that Confucian geopolitical theory is more of an ideal political geography script that can fail in real political practice. It is precisely because of the leniency (or looseness) in Confucianism that many actual politicians have been reluctant to adopt such strategies to 
achieve their political ambitions, especially in troubled times (luanshi). Conversely, in eras of peace (zhishi), Confucianism seems to be given more credit. In this regard, we need to carefully examine the connection and differences between the Confucian geopolitical narrative and China's geopolitical practice when discussing Chinese geopolitics, as they can-and dodiverge. In this sense, we need to be attuned to the convergences and divergences of script and practice.

\section{Revolt and Reflection: Confucian Theory in Communist China}

Throughout history, Confucian thought has profoundly influenced Chinese political culture, even if such thought has primarily existed in the form of an ideal political geography structure that is loosely practiced in real politics. However, during the era of the foundation of the People's Republic of China in 1949 (when the Chinese Communist Party took power), the significance of Confucianism in Chinese political culture markedly weakened. Chinese politics in this period was significantly affected by Maoist communism, which was both anti-capitalist and anti-tradition. However, although recent Chinese politics has also been characterised by the same anti-tradition sentiment, various studies find that tradition still plays an intricate role in Chinese political thought (Wang, 2018). This section therefore focuses on how Confucian tradition is still manifested in communist China and discusses how Confucianism influences current Chinese geopolitical theories. To understand how Confucian thinking has been mobilised in communist China, it is helpful to analyse it within two distinct historic periods: from the 1950 s to the 1970 s, characterised by radical communist geopolitics; and from the 1970 s to the present, characterised by Chinese socialist ${ }^{3}$ geopolitics.

The first period (1950s-1970s) was defined by the communist ideology. Chinese geopolitical views and practices during this period was imbued with strong anti-capitalist and anti-Western 
features - see Mao's elaborations in 'The Capitalist Road Does Not Work in China' as well as Mao's attitude towards traditional cultures (Chinese Communist Party's Archives Research Centre, 2003: 429-431, 1553-1559). That is, Confucian thought in communist China was disregarded in mainstream geopolitical thinking during this period. The most single significant geopolitical strategies at this time for China was to stand with the Soviet Union. However, this alliance was soon rocked by a series of geopolitical events, including the Bandung Conference (1954), the requirements for the Soviet Union to build submarine bases and there being common fleets in the South China Sea (1958), China becoming a permanent member of the United Nations (1971), and the proposal of Mao Zedong's Three Worlds Theory ${ }^{4}$ (1974), which together shaped a geopolitical convulsion that pushed China to reconsider the geopolitical alliance with the Soviet Union and its own geopolitical path. In 1971, China was formally elected as a permanent member of the United Nations, giving China a solid diplomatic foundation, which provided great political confidence in the transformation of China's geopolitical thinking at that time. Consequently, the Chinese ruling powers began to derail from the Cold War geopolitical logic and to reconsider the role of external and traditional geopolitical thinking.

Thus, the second period (1970s-present) demonstrates a uniquely Chinese approach to socialist geopolitics. In this period, Chinese socialist leaders selectively reused Confucian geopolitical values to explain current Chinese geopolitics. On the one hand, under the influence of globalisation as well as China's in-depth participation in international affairs, China is increasingly aware that it is deeply embedded in globalised economic, political, and cultural systems, which essentially obscures the Confucian binarism between the Chinese nation (Hua) and foreigners (Yi/Yang). In this regard, China has accepted the significance and role of the nation-state system in world politics, and has abandoned both the Hua-Yi division and a Sino- 
centric hierarchy. These changes are expressed in one of the key foreign policies of current China, 'The Five Principles of Peaceful Coexistence', introduced by former Chinese Prime Minister Zhou Enlai in his meeting with an Indian delegation, and thereafter established as the core of Chinese foreign policy (Keith, 2009). The policy highlights equality and mutual benefit; mutual respect for state sovereignty and territorial integrity; and non-aggression, noninterference in other state's affairs, and peaceful coexistence among different states. The new policy statement effectively removes any Sino-centric hierarchy from Chinese geopolitical theory (Keith, 2009). On the other hand, during this period, China has actively integrated its unique cultural heritage into the political ideal of communism by reconsidering the role of cultural continuity (in particular, the Confucian mindset). That is, the geopolitical convulsion that occurred during the earlier period has finally led to a more meaningful reintegration of Confucianism to create a distinctly Chinese version of socialism. The particularity in this Chinese version of socialist geopolitics can mainly be observed in the emphasis on Confucian philosophies.

Before explaining the Confucian geopolitical dimension of current Chinese politics, it is essential to discuss how Confucian values participate in domestic Chinese governing practices, beginning with China's current policy of 'governing the country with morality' (yide zhiguo). In the process of exploring socialism with Chinese characteristics, the Chinese government and socialist leaders have gradually established a set of ways to govern the country that have relied on both law and morality (Jiang, 2006). To some extent, the morality emphasised here is precisely a way for the traditional Chinese Confucian mindset to participate in modern Chinese governance. More specifically, we can find many Confucian traditions in the morality emphasised by socialist China. For example, the proposal of 'socialist moral construction' (shehuizhuyi daode jianshe) by Jiang Zemin (2006), the promotion of 'socialist views on 
honour and disgrace' (shehuizhuyi rongru guan) by Hu Jintao (2016), and the consolidation of 'socialist core values' (shehuizhuyi hexin jiazhiguan) by Xi Jinping (2017) —all of them interpretations of morality by these Chinese socialist leaders - can find a basis in Confucian classics, such as the Confucian advocacy of self-transcendence, harmony, and humaneness. This is a way for the ruling power to use morality as a narrative strategy to guide the behaviour of various groups in current Chinese society.

The influence of classic Confucian geopolitical theory based on current Chinese geopolitical views is manifested in two aspects. The first is reflected in most geopolitical discourses of China today. For example, China has gradually unveiled its ambition for expanded global engagements, as mentioned at the beginning of this paper, through projects like the BRICS, the BRI, and the FOCAC. China's rise has been increasingly discussed as a threat to changes in the global geopolitical landscape (Jeffery, 2009), whereas the Chinese governing powers have gradually applied the idea of harmony as a geopolitical discourse to establish a uniquely Chinese geopolitical framework. In many occasions, the importance of establishing a harmonious and multipolar international community has been emphasised repeatedly by a succession of Chinese Communist leaders and quotations from Confucian classics underscore the origins of their thinking (see Deng, 1994; Jiang, 2006; Hu, 2016; and Xi, 2014, 2017). This Confucian underpinning in China's current geopolitical discourse is particularly evident in the discursive repackaging of China's economic interventions in Africa, where China claims a moral supremacy compatible with the profit logic, reminiscent of the Chinese socialist views of morality-profit (Liu and Lou, 2018). In this discourse, Chinese leaders remark that China's economic presence in Africa should balance the morality-profit relationship and establish a model of economic relations in which there could be more morals and less profits, and even full morals and no profit. 
The second aspect is reflected in the geopolitical deployments of China, most of which regard the Confucian cultural legacies as an important theoretical basis for geopolitical strategies. Taking China's BRI as an example because of its striking resonances with Mckinder's (1904) Heartland theory in terms of the concerned geographical regions: the BRI is frequently linked to China's ambition to seek geopolitical domination over the Eurasian continent (e.g. Clover and Horny, 2015). Even studies that draw on Chinese-language writing in the BRI discuss how China's geopolitical strategies are articulated in China's intellectual productions, underlining how China attempts to legitimise its ambition for a new economic order (Sidaway and Woon, 2017). However, in fact, they ignore a key part of the BRI, namely its Confucian cultural orientation. Confucianism emphasises that the laws of interactions among various polities are based on connections of the mind rather than materials (i.e. Confucianism as a discussion of the balance between morality and profit), so the most important part of the BRI is actually the cultural purpose. Although the BRI emphasises a loose spatiality of economic cooperation (like the loose Hua-Yi mapping in ancient China), its essence still lies in a cultural dimension (just like the main basis of Confucianism for the discrimination of what is Hua and what is $\mathrm{Yi}$ in ancient China). Specific to the BRI, according to the relevant explanatory documents released by the Chinese government, its core concepts are mutual learning and complementarity (huxue, hujian, hubu) which aim to promote inter-cultural understanding, identification, and integration in order to achieve effective communication among various cultures. In an era of populism, xenophobia, and extreme right-wing tendencies in global cultural shift (McCarthy, 2019), the cultural spirit advocated by the BRI undoubtedly has very important cultural strategic value.

From these examples, we can see how present-day Chinese governing powers have discursively mobilised traditional thinking (particularly from Confucian philosophies) to create 
a framework for current Chinese geopolitics, ${ }^{5}$ thereby setting China apart from both Sovietstyle communism and Western countries. To a notable extent, these distinctly Chinese socialist geopolitics can be read as using the language of Confucianism as part of a narrative of Chinese exceptionalism: China is not the Soviet Union, nor is it a Western country; it is a different sort of global power that claims to be driven by morality and the search for harmonious order. While certainly bound to geopolitical narratives of power, morality, and difference, China nonetheless expresses and arranges them differently.

In addition to the reintegration of Confucian philosophies into current Chinese geopolitical narratives, Chinese socialist geopolitics are also characterised by the integration of external geopolitical and economic theories. Taking neoliberalism as an example, this mode of production has been an important factor in China's current economy (Harvey, 2005). Alongside China's 'open and reform policy' in the 1970s, the marketisation and privatisation that were advocated by neoliberalism has transformed the fabric of Chinese society. In Zhu's (2006) analysis of China's housing reform, and He and Wu's elaborations on China's urbanism (2010), neoliberalism is found to be an important geopolitical element that triggers tensions between the central and local government, increases social polarisation and spatial segregation, and heightens opposition between the state and markets. In the international arena, the liberalisation of capital controls is considered by ruling powers to be essential to the fulfilment of China's geopolitical objective to challenge the US-centred global geo-economic structure (Vermeiren and Dierckx, 2012). In this context, neoliberalism significantly impacts and guides Chinese geopolitical practices. Once again, there is a need to be wary of the difference between Chinese geopolitical narrative and practice. The influence of neoliberalism on China's geopolitics is obvious at the practical level. Nevertheless, the term 'neoliberalism' remains relatively taboo at the level of official discussion. This demonstrates once again the analytic need to separate 
Chinese geopolitical practice and narrative with a more critical perspective when discussing Chinese geopolitics.

In summary, we can see that the selective (or, perhaps more correctly, the strategic) use of Confucian traditions and narratives of Chinese exceptionalism to maintain the vitality and ongoing significance of present Chinese geopolitics. However, despite the influence of Confucianism on Chinese geopolitics, it has evolved to include elements from communist ideology and other geopolitical and geo-economic systems. In this regard, we assert that current Chinese geopolitics is neither a direct continuation of classic Confucian theory, nor is it a simple imitation of communist geopolitics or other geopolitical forms. Current Chinese geopolitical theories and practices are a strategic blend of the traditional Chinese philosophy of Confucianism along with communist elements and other external geopolitical theories. Therefore, we suggest that present-day Chinese geopolitics is grounded in a framework of classic Confucian theory, but that it is also much more than that.

\section{Hybrid Confucian Geopolitics}

Current Chinese geopolitics cannot be fully understood through the framework of classic Confucian theory. Instead, we recognise the complex weaving of Confucian ideals into the fabric of other social and economic factors in Chinese geopolitical thinking. We thus propose a theoretical framework of 'hybrid Confucian geopolitics' in which to situate the historical and geographical complexity of Chinese geopolitics.

Our hybrid theory not only acknowledges the strong role of Confucianism in the continuity of ancient Chinese culture up to the present but also emphasises the strategic adaptability of Confucianism to allow mainstream Chinese political culture to respond in new ways to 
changing contexts (for example, in the Han Dynasty, the Tang-Song-Ming Dynasties, and communist China). In other words, this hybrid theory acknowledges that factors other than Confucianism have influenced Chinese geopolitics, while simultaneously recognising the important role that Confucian thinking continues to play in supporting and legitimising state power. Such a perspective attempts to bring to the forefront of Chinese geopolitical study the widely shared, but often implicit, Confucian elements, while also examining other possible explanations for modern Chinese geopolitics. This hybrid theory views the Confucian geopolitical tradition as the foundation for current Chinese geopolitics, yet also leaves space for analysing how contemporary power structures strategically interpret (and appropriate) Confucianism into their practices.

First, in our model, Confucianism is a vital and lively culture that conditions Chinese society and Chinese geopolitics. This is not only reflected in the example of the BRI mentioned above, which has proposed a loose global framework based on Confucian culture in the context of global cultural shift, but also in how Confucianism has been practiced to varying degrees by Chinese politicians in different periods (both historical and modern). For example, several generations of Chinese communist leaders have discussed the importance of developing ancient Chinese culture within contemporary Chinese political narratives. Deng Xiaoping (1994) emphasised the importance maintaining social stability for China's long-term development; Hu Jintao (2016) theorised the Confucian idea of constructing a harmonious society into a distinctly Chinese socialism theory. When Xi Jinping came to power, he used Confucianism's views on morality-profit as a very clear moral dimension for guiding China's diplomatic practices, and in so doing he distinguished Chinese geopolitics from the interestbased and zero-sum model of realist geopolitics (Xi, 2017). These cases show that the tradition of Confucianism is being widely mobilised in the grand political narrative structure of present- 
day China. In this sense, the influence of Confucianism on current Chinese politics is not a passive choice, but rather a strategic initiative buoyed by historical pathways. It is not a blind acceptance of the classic Confucian geopolitical theory, but rather selective reuse and reorganisation of Confucian values.

Second, and most importantly in our model, Confucianism is inclusive of other geopolitical and geo-economic cultures, and the adaptability and openness of Confucian culture to other ways of thinking is an important component of hybrid Confucian geopolitical theory. Since late Qing China, Chinese culture has continuously experienced challenges and influences from outside cultures. The challenges have come primarily from the West, including several movements to spread Western-style education to China, as well as the 'reform and opening-up policy'. These movements have brought new kinds of political and economic thinking into China, and in so doing have influenced Chinese geopolitical views. The spread of Western-style education to China, for example, has promoted modern nationalist thinking, which stresses national identity, national equality, national independence, and the consciousness of national suffering (Zheng, 2006). Later, when Marxist and communist ideology arrived in China, such ideas quickly became established as mainstream cultural values, and they tended to exert a strong influence on Chinese political culture. On the other hand, the 'reform and opening-up policy' opened China to other Western philosophies. Neoliberal ideas, developed during the post-reform era, are important elements shaping the current practice of Chinese geopolitics across the globe (even if rarely spoken) (Zhu, 2006; He and Wu, 2010; Vermeiren and Dierckx, 2012). Despite several challenges associated with it, however, Confucianism has been adjusted to fit with outside cultures, and simultaneously, has adapted external cultures to fit with itself. This helps explain why the ruling powers in China have called for inheriting excellent cultural traditions from ancient Chinese philosophies, while simultaneously adopting outside ways of thinking 
that might benefit China. This point is also evident in the case of the BRI. Although we have argued that the essence of the BRI is a cultural strategy with Confucianism at its core, it is undeniable that the BRI is structurally symbiotic with the free trade system between countries and regions which, to a great extent, can be interpreted as a consequence of being influenced by neoliberal thinking.

Confucian philosophies are thus essential to our understanding of current Chinese geopolitics, even if they have been largely ignored in the existing literature on Chinese geopolitics. We therefore argue that Confucian elements need to be brought back into Chinese geopolitical studies to be studied alongside nationalist, communist, neoliberal, and other socioeconomic forces to understand the Chinese geopolitics of today. To accomplish this, we advocate a hybrid Confucian geopolitical model, emphasising Confucian values as foundational (yet mutable) ideals for explaining Chinese geopolitics, and simultaneously acknowledging other influences on Chinese geopolitics. Just as the term 'critical geopolitics' has brought together two terms that were considered contradictory (Sharp, 2013), there seems to be a contradiction in the term 'Confucian geopolitics'. The term 'Confucian' focuses on harmony, hierarchy, and social order, whereas 'geopolitics' analyses geographical influences on politics - in particular, on violence and conflict. The concept 'Confucian' looks like an antique with thousands of years of history, whereas the term 'geopolitics' is largely embedded in the modern political system with a strong anti-tradition sentiment. Most importantly, whether in ancient or modern China, there is a tension between the narratives and practices of Confucianism. However, it is exactly within these contradictions that a new way of thinking about geopolitics can emerge. This study has attempted to trace the influence of ancient Chinese cultures on current Chinese geopolitics to better understand the role of China in a multipolar world — from a Chinese perspective. 
Given that 'hybrid Confucian geopolitics' exerts an ongoing influence on contemporary international geopolitics, we expect that this model could be used to examine other Chinese geopolitical rhetoric and practices in the future. For example, as the influence of China in the international political and economic arena continues to rise, geopolitical events related to China have become the focus of the world, such as the BRICS, the BRI, the FOCAC, China's participation in global environmental governance, and China's participation in polar affairs. These events do not easily map onto Western imaginations and geographies, and they require their own heuristic. In this regard, the 'hybrid Confucian geopolitics' model gives theoretical space to understanding China as a unique, non-Western actor with centuries of cultural, political, and economic changes. These changes continue today, as China adapts to other global geopolitical powers.

\section{Notes}

1. In fact, when we talk about China, Chinese culture, and Chinese identity as a whole, it is easy to fall into the danger of essentialism in terms of national homogenisation. Here, I agree with Chun's (1996) perspective, which emphasises that China is by no means an ethnic, cultural, and identity-homogeneous unit, as it has one-fifth of the world's population, 56 ethnic groups, the challenge of national unification, and around five millions of Chinese nationals living abroad. This notion, therefore, needs to be cautiously clarified, as it is used in various contexts. In this paper, 'China' mostly refers to a country with an independent territory and sovereignty, while 'Chinese culture' and 'Chinese identity' refer to a heritage of the habits of the people who have lived on this land for thousands of years, not limited to any one country or ethnicity.

2. There is indeed a great ambiguity in understanding 'Chineseness' (see note 1). Here, 'Chineseness' refers to the coalescence of political (territorial) and cultural dimensions in understanding the idea of China, although the two dimensions do not completely overlap.

3. The Chinese Communist Party insists that communism is an ideal type of social form, while China is currently, and will be for a long time, at the primary stage of the communist social form. The Chinese 
Communist Party, therefore, widely uses the term 'socialist' when referring to this communist ideology.

4. In February 1974, when Mao was meeting with Kenneth Kaunda, the Zambian president who was visiting China, he said, 'I see the United States and the Soviet Union are the first world; Japan, Europe, and Canada, the centrists, are the second world; while we are the third world', which was subsequently developed as the Three Worlds Theory.

5. Here, it is noteworthy that the mobilisation of Confucian philosophies for the present-day Chinese geopolitical framework is not a holistic acceptance of the past. The current Chinese state seems to have been selectively revitalising some of these Confucian ideas. However, it is also happy to pass by a few aspects of Confucian philosophies, such as 'sagacity within and kingliness without', 'Hua-Yi distinction', and 'Sino-centric hierarchy'.

\section{References}

Agnew J (2010) Emerging China and critical geopolitics: Between world politics and Chinese particularity.

Eurasian Geography \& Economics 51(5): 569-582.

Agnew J (2012) Looking back to look forward: Chinese geopolitical narratives and China's past. Eurasian

Geography \& Economics 53(3): 301-314.

An N, Cai X, and Zhu H (2017) Gaps in Chinese geopolitical research. Political Geography 59: 136-138.

An N, Liu C, and Zhu H (2016) Popular geopolitics of Chinese Nanjing massacre films: A feminist approach. Gender, Place \& Culture 23(6): 786-800.

Blanchard JMF, and Flint C (2017) The geopolitics of China's Maritime Silk Road Initiative. Geopolitics 22(2): $223-245$. 
Brewster D (2017) Silk roads and strings of pearls: The strategic geography of China's new pathways in the Indian Ocean. Geopolitics 22(2): 269-291.

Callahan W A (2004) Contingent States: Greater China \& Transnational Relations. Minneapolis:

University of Minnesota Press.

Callahan W A (2010) China: The Pessoptimist Nation. Oxford: Oxford University Press.

Callahan W A (2012) Sino-speak: Chinese exceptionalism and the politics of history. Journal of Asian Studies 71(1): 33-55.

Carmody P, and Owusu F (2007) Competing hegemons? Chinese vs American geo-economic strategies in Africa. Political Geography 26(5): 504-524.

Chen L (2015) Zhonghua wenming de hexin jiazhi (The Core Values of Chinese Civilization). Beijing: Joint Press.

Chen XK (2005) Yuanshi ruxue he ruxue de zongjiaohua (Primary Confucianism and Confucianism's Religionization). Xi'an jiaotong daxue xuebao (Journal of Xi'an Jiaotong University) 25(3): 89-92. Chinese Communist Party's Archives Research Center (2003) Mao Zedong zhuzuo zhuanti zhaibian (Excerpts from Mao Zedong's Monographs). Beijing: The Central Archive Publishing House. Chinese History Research Institute (1982) Zhongguo lishi yanjiu ziliao congshu (Chinese Historical 
Research Data Series). Shanghai: Shanghai Bookstore.

Chun A (1996) Fuck Chineseness: On the ambiguities of ethnicity as culture as identity. Boundary 2 23(2):

111-138.

Clover C, and Horny L (2015) China's Great Game: Road to a new empire. Financial Times 12 October.

http://www. ft.com/cms/s/2/6e098274-587a-11e5-a28b-50226830d6 44.html\#axzz4E2lfcpOT

Dalby S (2013) Realism and geopolitics. In Dodds K, Kuus M, and Sharp J (eds.) The Ashgate Research

Companion to Critical Geopolitics. Burlington, VT: Ashgate Publishing, 33-48.

Deng XP (1994) Deng Xiaoping xuanji (Deng Xiaoping's Anthology). Beijing: People’s Press.

Feng AB (2011) Lun 20 shiji chu huayiguan xiang jindai minzuguan de zhuanbian (Discussion on the

transformation from Chinese 'Hua-Yi' concept to modern nation concept in early 20th century). Qiusuo

(Explorations) 7: 244-246.

Gao HT (1999) Yingshi magaerni fanghua (The British Ambassador Macartney’s Visiting of China).

Zhongguo dangan (Chinese Archives) 6: 46-47.

Ge Q (2000) Liming yu zhongcheng: shiren zhengzhi jingshen de dianxing fenxi (Life and loyalty: A typical

analysis of the political spirit of Confucian scholars). Hangzhou: Zhejiang People's Press.

Han Q (1999) Ruxue de san da zhuanzhe (Three major turnings in Confucianism). Zhongguo Zhexueshi 
(History of Chinese Philosophy) 3: 27-35.

Han X (2014) Huayi zhi bian jiqi jindai zhuanxing (Differentiating hua and yi and its recent transition).

Dongfang luntan (East Forum) 5: 1-8.

Hang L (2011) Traditional Confucianism and its contemporary relevance. Asian Philosophy 21(4): 437-

445.

Harvey D (2005) A Brief History of Neoliberalism. Oxford: Oxford University Press.

He SJ, and Wu FL (2010) China's emerging neoliberal urbanism: perspectives from urban redevelopment.

Antipode 41(2): 282-304.

Hu JT (2016) Hu Jintao xuanji (Hu Jintao's Anthology). Beijing: People's Press.

Hughes C (2000) Nationalism in Chinese cyberspace. Cambridge Review of International Affairs 13(2):

195-209.

Jacques M (2009) When China Rules the World: The End of the Western World and the Birth of a New

Global Order. New York: Penguin.

Jeffery R (2009) Evaluating the 'China Threat': Power transition theory, the successor-state image and the dangers of historical analogies. Australian Journal of International Affairs 63(2): 309-324.

Jiang ZM (2006) Jiang Zemin xuanji (Jiang Zemin's Anthology). Beijing: People’s Press. 
Kang D C (2007) China Rising: Peace, Power and Order in East Asia. New York: Columbia University Press.

Keith R (2009) China from the Inside Out: Fitting the People's Republic into the World. London: Pluto

Press.

Legge J (2010) The Analects of Confucius. Auckland: The Floating Press.

Li J (1993) Geopolitics of the Chinese communist party in the twentieth century. Sociological Perspectives 36(4): 315-333.

Li JH (2004) Zhongguo gudai shaoshu minzu qianxi yuanyin tantao (The reasons for migration of ancient

Chinese ethnic groups). Zhongnan minzu daxue xuebao (Journal of South-Central University for

Nationalities) 24(1): 71-75.

Li XQ (2013) Chushi qinghuajian (First Meet with Tsinghua Bamboo Slips). Shanghai: Chinese and

Western Bookstores.

Liang QC (2006 [1902]) Lun zhongguo xueshu sixiang bianqian zhi dashi (On the General Trend of

Changes of Chinese Academic Thoughts). Shanghai: Shanghai Ancient Press.

Liu L, and Lou YP (2018) Xi Jinping waijiao sixiang de lunli weidu (The ethical dimension of Xi Jinping's diplomatic thought). Dangdai shijie shehuizhuyi wenti (Issues of Contemporary World Socialism) 2: 
$13-19$.

Liu XD (2011) Huayi yijia yu xin dayitong (The whole family of 'Hua' and 'Yi', and new Great Unity).

Xuexi yu tansuo (Study \& Exploration) 2: 250-252.

Liu ZM (2009) Shijie haiyang zhengzhi yu zhongguo haiyang fazhan zhanlve (World Marine Politics and

China's Marine Development Strategies). Beijing: Current Affairs Press.

Mackinder H (1904) The geographical pivot of history. The Geographical Journal 23(4): 421-437.

Manson GP (2010) Contending nationalisms: China and India march into the twenty-first century. Asian

Affairs: An American Review 37(2): 85-100.

Maswana JC (2009) A center-periphery perspective on Africa-China's emerging economic links. African

and Asian Studies 8(1): 67-88.

McCarthy J (2019) Authoritarianism, populism, and the environment: Comparative experiences, insights,

and perspectives. Annals of the American Association of Geographers 109(2): 301-313.

Ning XC (1998) Benti yu jingjie: lun song-ming xin ruxue de jingshen (Ontology and realm: on the spirit of Song-Ming neo-Confucianism). Kongzi yanjiu (Confucius Study) 4: 63-73.

Overholt W (2007) Asia, America, and the Transformation of Geopolitics. Cambridge: Cambridge University Press. 
Pan QZ (2011) Lun yangming xinxue dui ruxue lilun xingtai de zhuanxing jiqi qishi (On the impact of

Yang-Ming Theory on the transformation of Confucianism). Zhejiang shehui kexue (Zhejiang Social

Sciences) 12: 108-115.

Park J (2015) Is the Chinese government's increase in development co-operation with Africa the revival of

Sinocentrism? Geopolitics 20(3): 626-644.

Qi CF (2000) Shaoshu minzu tongzhizhe yu ‘huayi zhi bian' guan (The rulers of national minority political powers and the view of 'Hua-Yi division'). Neimenggu daxue xuebao (Journal of Inner Mongolia University) 38(6): 28-34.

Qin P (2010) Chunqiu guliangzhuan huayi sixiang chutan (Primary discussion about the idea of Hua-Yi in Ku-Liang Exegesis of Chun-Qiu). Qilu xuekan (Qilu Journal) 214(1): 13-17.

Ren HG (2001) Shi lun Lu Gu dui ruxue de gaizao (Debate on Lu Gu's reform on Confucianism). Yantai shifan xueyuan xuebao (Journal of Yantai Normal University) 18(4): 12-17.

Rolf S, and Agnew J. (2016) Sovereignty regimes in the South China Sea: Assessing contemporary SinoUS relations. Eurasian Geography \& Economics 57(2): 1-25.

Said E (1978) Orientalism. London: Penguin Books.

Scott D (2008) The great power 'Great Game' between India and China: 'The logic of geography'. 
Geopolitics 13(1): 1-26.

Sharp J (2013) Geopolitics as the margins? Reconsidering genealogies of critical geopolitics. Political Geography 37(1): 20-29.

Shlapentokh V (1995) Russia, china, and the far east: old geopolitics or a new peaceful cooperation?

Communist and Post-Communist Studies 28(3): 307-318.

Sidaway J D, and Woon C Y (2017) Chinese narratives on “One Belt, One Road” (一带一路) in geopolitical and imperial contexts. The Professional Geographer 69(4): 591-603.

Sun YY, and Ge Q (2017) Zhengzhi wenhua shiyu xia ruxue de benzhi xilun (An analysis of the essence of Confucianism from the lens of political culture). Xuexi yu tansuo (Study \& Exploration) 11: 91-98.

Treadgold DW (1977) Chinese communism: Foreign prospects. Asian Affairs 4(5): 317-341.

Vermeiren M, and Dierckx S (2012) Challenging global neoliberalism? the global political economy of china's capital controls. Third World Quarterly 33(9): 1647-1668.

Wang FS (2018) Zhongguo jindai sixiang yu xueshu de xipu (The Pedigree of Modern Chinese Thought and Scholarship). Shanghai: Joint Press.

Wang SE (2003) Huayi zhi bian dui minzu ronghe de yingxiang (The influence of ‘Hua Yi Division' on national integration). Nandu xuetan (Academic Forum of Nan Du) 23(5): 26-30. 
Woon CY (2012) Comment on looking back to look forward: Geopolitics, identity, and engaging China.

Eurasian Geography \& Economics 53(3): 331-337.

Woon CY (2018) China's contingencies: Critical geopolitics, Chinese exceptionalism and the uses of

history. Geopolitics 23(1): 67-95.

Wu G (2008) From post-imperial to late communist nationalism: historical change in Chinese nationalism

from May Fourth to the 1990s. Third World Quarterly 29(3): 467-482.

Xi JP (2014) Xi Jinping tan zhiguo lizheng (di yi juan) (Xi Jinping Talks about the Statecraft (Volume 1)).

Beijing: Foreign Languages Press.

Xi JP (2017) Xi Jinping tan zhiguo lizheng (di er juan) (Xi Jinping Talks about the Statecraft (Volume 2)).

Beijing: Foreign Languages Press.

Xu G (2012) Chinese anti-Western nationalism, 2000-2010. Asian and African Studies 9(2): 109-134.

Xu ZY (2015) Wozhe yu tazhe: zhongguo lishi shang de neiwai fenji (Self and Other: The Division of

Inside and Outside in Chinese History). Beijing: Joint Press.

Yang SS (2001) Lun rujia yili guan de lishi yanbian ji xiandai yiyi (The historical changes of the

Confucian views of morality-benefit and the discussion of its modern meaning). Shehui kexue jikan

(Social Science Series) 2: 19-24. 
Yao X (2000) An Introduction to Confucianism. Cambridge University Press.

Zeng J, Xiao Y, and Breslin S (2015) Securing China's core interests: The state of the debate in China. International Affairs 91(2): 245-266.

Zhang B, and Zhang YZ (2010) Qingdai wenziyu yanjiu shuping (Studying on literary prisons in Qing Dynasty). Xibei shifan daxue xuebao (Journal of Northwest Normal University) 47(3): 55-62.

Zhang K (2009) Zhongguo he shijie diyuan youqi (China and World Geo-petroleum). Beijing: Geological Press.

Zhao TY (2008) Tianxia tixi de yige jianyao biaoshu (An introduction to Tianxia system). Shijie jingji yu zhengzhi (World Economics and Politics) 10: 57-66.

Zheng DH (2006) Zhongguo jindai minzu zhuyi de laiyuan, yanbian yu qita (The origin and evolution of Chinese modern nationalism). Shixue yuekan (History Monthly) 6: 10-13.

Zhou YM (2005) Informed nationalism: military websites in Chinese cyberspace. Journal of Contemporary China 14(44): 543-562.

Zhu YP (2006) Urban governance, neoliberalism and housing reform in china. Pacific Review 19(1): 3961. 